\title{
Azurin Synthesis from Pseudomonas Aeruginosa MTCC 2453, Properties, Induction of Reactive Oxygen Species, and p53 Stimulated Apoptosis in Breast Carcinoma Cells
}

\author{
Sankar Ramachandran ${ }^{1}$, Siddik Sarkar ${ }^{1}$, Abhijit Mazumadar $^{2}$ and Mahitosh Mandal ${ }^{\text {* }}$ \\ ${ }^{1}$ School of Medical Science \& technology, Indian Institute of Technology, Kharagpur, West Bengal, India \\ ${ }^{2}$ Department of Clinical Cancer Prevention, Unit 1360, The University of Texas MD Anderson Cancer Center, 1515 Holcombe Blvd, Houston, TX 77030
}

\begin{abstract}
Breast cancers are usually treated with surgery and radiation excretes adverse effects. Azurin, a potent anticancer redox protein secreted by Pseudomonas aeruginosa ( $P$. aeruginosa) species has been reported to have activity against breast cancer cell lines; this had prompted researchers to search for novel methods to enhance this protein's production. Researchers previously have reported on the synthesis of blue copper protein azurin from different microbial sources specifically from $P$. aeruginosa. Our investigation used customized methods to focus on synthesizing azurin from different strains of $P$. aeruginosa with apparent homogeneity. We screened the growth of different $P$. aeruginosa strains $(1934,741,2453$, and 1942) for the synthesis of azurin and for enhanced azurin production. We exposed azurin properties using matrix-assisted laser desorption/ionization, sodium dodecyl sulfate polyacrylamide gel electrophoresis and Fourier transform infrared spectroscopy. Additional studies of possible molecular mechanisms and reactive oxygen species (ROS) generation of $P$. aeruginosa 2453 secreted azurin are needed. We examined which strain among $P$. aeruginosa strains 1934, 741, 2453, and 1942 best enhanced azurin production. Our current study also revealed which strain of the four had the strongest antiproliferative effect of azurin. P. aeruginosa MTCC (Microbial Type culture collection) 2453 was the strain that secreted the most azurin and showed remarkable apoptosis in breast carcinoma cells like T- 47D and ZR-75-1. This study demonstrates customized methods to synthesize azurin from different strains of $P$. aeruginosa with apparent homogeneity and their apoptotic effects on breast carcinoma cells with possible molecular mechanisms and ROS.
\end{abstract}

Keywords: Azurin synthesis; MALDI-ToF; FTIR; Brest Cancer; ROS; Apoptosis

\section{Introduction}

Among cancer incidence breast cancer comprises $10.4 \%$ among women than men alarmingly high. With such intense spread, treatment for breast cancer is indispensable. The search for new drugs developed from microbial sources and used to treat infectious disease began when Alexander Fleming discovered penicillin [1]. The secondary metabolites from microorganisms play a vital role in developing chemotherapeutics [2]. Several researchers have reported that various anticancer molecules can be obtained from different microbial sources. Even though chemotherapy is efficient in enhancing patient survival with primary tumors continue to have deprived prognosis. Azurin, a redox protein, recently captured the interest of biomedical researchers as an anticancer therapeutic agent that can enter human breast cancer cells and induce apoptosis mediated by the tumor suppressor P53 protein [3]. Previously [4-6] live or attenuated pathogenic bacteria or their metabolites were used to treat cancer but they excreted toxic effects in patients.

Earlier in vivo studies have elaborated on how azurin triggers p53 and subsequently induces apoptosis in breast cancer cells [3]. P53 plays a major role in pathogenesis of neoplasia [8]. A significant increase in the protein level of p53 mediates various cellular responses including deoxyribonucleic acid (DNA) damage, $\mathrm{G}_{1}$ arrest, and induction of apoptosis [9]. P53-mediated apoptosis is a transcription factor that is activated as part of the cell's response to stress and which regulates several downstream genes [10-13].

Amid assorted signaling pathways, intracellular caspases play a key role in apoptotic cell death $[10,13]$. The caspase family of cysteine proteases is directly or indirectly responsible for the cleavage of cellular proteins, which are typically proteolysed during apoptosis [14]. Some caspases cleave DNA interaction with Poly (adenosine diphosphate (ADP)-ribose) polymerase (PARP) and which can deplete the ATP of a cell ATP depletion in a cell leads to cell lyses and cell death. Bcl-2associated X protein (Bax), a mammalian protein of the Bcl-2 family, acts as an antiapoptotic or a proapoptotic regulator that is involved in a wide variety of cellular activities leading to caspase activation [7,11-13] Moreover, Bax is upregulated by tumor suppressor protein $\mathrm{p} 53$, which also promotes Bax insertion into the mitochondrial membranes [1112].

Since azurin has been reported to be a potential anticancer protein against breast cancer cell lines [7], researchers are searching for novel methods to enhance its production of azurin. Synthesis of a pure microbial metabolite like azurin from $P$. aeruginosa strain 2453 reduces toxic effects in regression of cancer treatment. Previous study reveals that the blue copper protein azurin with cytochrome $c$ can be synthesized from different microbial sources, specifically from P. aeruginosa [15]. Earlier, Sutherland [16] demonstrated the impact of $\mathrm{CuSo} 4$ and $\mathrm{KNO} 3$ with casein hydrolysate in the culture medium

*Corresponding author: Dr. Mahitosh Mandal, Assistant Professor, School of Medical Science and Technology, Indian Institute of Technology, Kharagpur, India. Tel: 91+3222-283578; E-mail: mahitosh.smst@iitkgp.ernet.in

Received October 15, 2010; Accepted November 17, 2010; Published March 15, 2011

Citation: Ramachandran S, Sarkar S, Mazumadar A, Mandal M (2011) Azurin Synthesis from Pseudomonas Aeruginosa MTCC 2453, Properties, Induction of Reactive Oxygen Species, and p53 Stimulated Apoptosis in Breast Carcinoma Cells. J Cancer Sci Ther 3: 104-111. doi:10.4172/1948-5956.1000069

Copyright: (C) 2011 Ramachandran S, et al. This is an open-access article distributed under the terms of the Creative Commons Attribution License, which permits unrestricted use, distribution, and reproduction in any medium, provided the original author and source are credited. 
Citation: Ramachandran S, Sarkar S, Mazumadar A, Mandal M (2011) Azurin Synthesis from Pseudomonas Aeruginosa MTCC 2453, Properties, Induction of Reactive Oxygen Species, and p53 Stimulated Apoptosis in Breast Carcinoma Cells. J Cancer Sci Ther 3: 104-111. doi:10.4172/1948-5956.1000069

for azurin synthesis. Even Pozdnyakova et al. [17] reported about the importance of adding copper in the culture medium which stabilizes the azurin structure. The presence of a copper ion in the polypeptide chain contributes to azurin's stability.

Therefore, our prospective study is focused on enhanced azurin synthesis from four different strains of $P$. aeruginosa $(1934,741,2453$, and 1942) with apparent homogeneity and stability by adding both $\mathrm{CuSo} 4$ and $\mathrm{KNO} 3$ in the culture medium.

Our interest also extended to analyze the differences in secondary structure of purified azurin from all strains and its impact on apoptosis with possible molecular mechanisms and ROS generation in breast carcinoma cells.

\section{Materials and Methods}

\section{Growth of $P$. aeruginosa strains}

To grow $P$. aeruginosa strains, we obtained analytical grade medium constituents from Hi-Media Laboratories, Mumbai, India. We procured lyophilized vials of $P$. aeruginosa MTCC strains 1934, 741, 2453, and 1942 from the Institute of Microbial Technology, Chandigarh, India. We grew and cultivated the strains in four different flasks in culture medium as [15] described in his procedure. In addition with this we added copper sulphate $(\mathrm{CuSo} 4)(5 \mu \mathrm{g} / \mathrm{ml})$ and potassium nitrate (KNO3) $(0.02 \mu \mathrm{g} / \mathrm{ml})$ to the medium.

\section{Azurin synthesis}

The purification and synthesis of azurin was performed using diethyl amino ethyl cellulose (DEAE) cellulose, sephadex G-25 and G-75, and CM cellulose chromatography $[15,18]$.

\section{Purification of azurin from $P$. aeruginosa strains}

According to Van de Kamp et al. [18] and Parr et al. [15] azurin was purified from all the $P$. aeruginosa strains, by centrifugation at 13,200 $\times \mathrm{g}$ for 15-20 min to collect the cell pellets. Collected cell pellets were sheared by ultrasonication for 1-2 min at $100 \mathrm{~W}$ in an ice basket for centrifugation at $10,000 \times \mathrm{g}$ for $20 \mathrm{~min}$. The supernatant was collected and stored at $4^{\circ} \mathrm{C}$.

The supernatant (crude) was precipitated initially to $45 \%$ and then finally to $95 \%$ by slowly adding ammonium sulfate salt at $4{ }^{\circ} \mathrm{C}$ for precipitation of proteins and kept it for overnight under stir mode. We centrifuged the overnight precipitated solution at 23,000 $\times$ g for 45 min. The azurin-containing precipitate was resuspended in $0.02 \mathrm{M}$ PBS buffer ( $\mathrm{pH}$ 7) for dialysis until it attains buffer $\mathrm{pH}$ to separate all small proteins and salts

\section{Azurin purification on chromatography}

Ion Exchange Chromatography: The dialysate of all strains were initially treated with DEAE cellulose cationic exchanger as described by Parr et al. [15].

\section{Gel filtration chromatography}

According to Parr et al. [15] the proteins after anionic separation were subsequently separated through gel filtration using Sephadex G25 and followed by a Sephadex G-75 column. The sample was applied in columns and eluted with $0.02 \mathrm{M}$ PBS, pH 7 and $0.01 \mathrm{M}$ Tris/Hcl buffer $\mathrm{pH} 7.5$ respectively at a flow rate of $1 \mathrm{ml} / \mathrm{min}$.

\section{Ion exchange chromatography on CM cellulose}

Azurin separation in CM cellulose: As described by Parr et al.
[15] we equilibrated the carboxymethyl (CM) cellulose beads, for azurin purification. Gently one $\mathrm{ml}$ of the sample (Fraction collected from G-75) was loaded over the column for 5-10 minutes to bind the protein inside the beads. After 10 minutes the column was eluted with ammonium acetate buffer $\mathrm{pH} 4.65$.

\section{Azurin properties}

Determination of molecular weight by MALDI: The fractions collected from CM cellulose chromatography of all strains performed MALDI. We added a 2- $\mu \mathrm{l}$ fraction of CM cellulose chromatography from all $P$. aeruginosa strains to $20 \mu$ l of 3, 5-dimethoxy, 4-hydroxy cinnamic acid, also known as sinapinic acid (Sigma-Aldrich, Kolkata, India). Small spots azurin were made on silver plate and dried for 4-6 hours to drain the water molecules. After they dried, the samples were placed in the MALDI chamber (Voyager De pro, Applied Systems, Illinois, USA) for analysis using a nitrogen laser at $337 \mathrm{~nm}$ [19].

\section{Confirmation of molecular weight by SDS-PAGE}

The samples collected during the chromatography steps were analyzed by SDS-PAGE according to Weber and Osborn [20] to determine the molecular weight of azurin. Proteins purified from CM cellulose chromatography of all strains were loaded with bromophenol (molecular weight marker dye) adjacent to standard protein marker lane.

\section{Fourier transform infrared spectroscopy (FTIR) analysis}

Infrared spectroscopy experiments were performed using a Nexus 870 (Thermo Nicolet Corporation, Madison, USA) spectrometer equipped with a potassium bromide $(\mathrm{KBr})$ beam splitter and a DTGS TEC (deuterated triglycine sulfate) detector in the range of 3,000-4000 $\mathrm{cm}^{-1}$. We recorded 32 scans per spectrum at a $2 \mathrm{~cm}^{-1}$ resolution [21] for $100 \mu \mathrm{l}$ of azurin liquid samples in 0.02 M PBS buffer ( $\mathrm{pH}$ 7.0). We kept the same buffer as a background medium and performed all measurements at room temperature. We corrected spectra for the moisture and carbon dioxide in the optical path. The curves were deconvoulted and imported into Omnic's peak fit software (Thermo scientific, Illinois, USA) and a Gaussian curve fitting was performed [21].

\section{The anti cancer effects of azurin on breast carcinoma cell lines}

Cell culture: For our experiments, we used breast carcinoma cell lines T- 47D and ZR-75-1 cultivated (Organ: Breast, Disease: Breast carcinoma; Organism: Human; procured from ATCC (American Type Culture Collection) in RPMI (Roswell park memorial institute medium -1640) and dimethyl sulfoxide (DMEM) medium respectively, enhanced with $10 \%$ fetal bovine serum (FBS), penicillin, L-glutamine, sodium pyruvate, nonessential amino acids, and vitamin solutions. We maintained adherent monolayer cultures in T-25 flasks and incubated them at $37^{\circ} \mathrm{C}$ in $5 \%$ carbon dioxide $\left(\mathrm{CO}_{2}\right)$. The cultures were free of mycoplasma and were maintained no longer than 12 weeks after being recovered from frozen stocks [9].

\section{MTT assay}

We obtained a customized thiazolyl blue tetrazolium bromide(MTT) powder and dimethyl sulfoxide (DMSO) solution (spectra grade) from Sigma Aldrich (Kolkata, India). Azurin from all $P$. aeruginosa strains was assayed primarily against T- 47D (P53 independent apoptosis) and further azurin from $P$. aeruginosa 2453 assayed against ZR-75-1 (P53 dependent apoptosis) breast cell lines using an MTT-based assay, which measures cell proliferation based on the ability of live cells to convert MTT into dark blue formazan crystals. T- 47D and ZR-75-1 
Citation: Ramachandran S, Sarkar S, Mazumadar A, Mandal M (2011) Azurin Synthesis from Pseudomonas Aeruginosa MTCC 2453, Properties, Induction of Reactive Oxygen Species, and p53 Stimulated Apoptosis in Breast Carcinoma Cells. J Cancer Sci Ther 3: 104-111. doi:10.4172/1948-5956.1000069

were trypsinized, enumerated, and accustomed to 1,000 cells/ well in $100 \mu \mathrm{l}$ of RPMI medium to all wells of the 96 -well plates. The next day, the medium was aspirated and $100 \mu$ of RPMI medium containing the desired concentration of azurin that had been synthesized from each strain was added to the appropriate wells. Cells then were incubated at $37^{\circ} \mathrm{C}$ in $5 \%$ carbon dioxide $\left(\mathrm{CO}_{2}\right)$ for $48 \mathrm{~h}$. After incubation, RPMI medium containing different concentrations of azurin from the wells was removed. We replaced $100 \mu \mathrm{l}$ of $5 \mathrm{mg} / \mathrm{ml}$ MTT reagent in each well, and the plate was incubated at $37^{\circ} \mathrm{C}$ for $2-6 \mathrm{~h}$. After incubation, we replaced the supernatant with $200 \mu \mathrm{l}$ of DMSO in each well. A colored formazan crystal was assayed spectrophotometrically at $570 \mathrm{~nm}$ using a plate reader (Bio- Rad Micro plate reader $5805 \mathrm{R}$, Gurgaon, India). The absorbance of the control plate, which was not seeded with any cells during initial plating, was subtracted from the absorbance of every other well [11-13].

\section{Cell cycle analysis}

Cell cycle analysis of the azurin treated breast cancer cells was performed using fluorescence activated cell sorting (FACS) scan (Becton Dickinson Immunocytometery Systems California, USA ) we evaluated the intensity of cytotoxicity because of induction of apoptosis. We seeded $10^{6}$ cells (ZR-75-1 (P 53 dependent cells) in $3 \mathrm{ml}$ of RPMI 1640 medium into 6 six-well culture plates. After $24 \mathrm{~h}$, cells were synchronized in incomplete medium supplemented with $2 \%$ FBS for $24 \mathrm{~h}$. The cells were treated with azurin $(72 \pm 3 \mu \mathrm{g} / \mathrm{ml}$ concentration) from each bacterial $P$. aeruginosa strain for $48 \mathrm{~h}$. We then took the azurin synthesized from $P$. aeruginosa 2453 and assayed it $(72 \pm 3 \mu \mathrm{g} / \mathrm{ml}$ concentration) against T- 47D and ZR-75-1 at intervals of $0,12,24,48$ h. After treatment, cells were harvested, washed twice with PBS, and centrifuged at 1,200 rpm for $5 \mathrm{~min}$ at room temperature. Supernatant was decanted, and cells were fixed with $70 \%$ ethanol overnight at $-20^{\circ} \mathrm{C}$. The cell suspension was then centrifuged, and $1 \mathrm{ml}$ solution of both propidium iodide and RNase in PBS were added to the pellet and then kept in the dark for $30 \mathrm{~min}$ at $37^{\circ} \mathrm{C}$ for incubation. Finally, cells were analyzed using Cell quest pro software (BD Biosciences, California, and USA) equipped with the FACS machine. The content of DNA was expressed as sub- $G_{1}, G 0 / G 1, S$, and G2/M phases [22-23].

\section{Estimation of ROS generation}

ROS levels of azurin (synthesized from $P$. aeruginosa 2453)treated breast cancer cells (ZR-75-1) were resolute using 2', 7' Dichlorofluorescin diacetate (DCFH-DA) as a probe during flow cytometry. Azurin-treated ZR-75-1 cells were harvested using Trypsin/ EDTA after treatment and resuspended in PBS. We then added $20 \mu \mathrm{M}$ $\mathrm{DCFH}-\mathrm{DA}$ for incubation at $37^{\circ} \mathrm{C}$ for $30 \mathrm{~min}$. Deacetylation occurs due to the intake of DCFH-DA by cells, forming a non-fluorescent DCFH. The DCFH fluorescent intensity was measured and correlated with the generated ROS [24-25].

\section{DNA fragmentation assay}

Both azurin (synthesized from P. aeruginosa 2453) treated and untreated ZR-75-1 cells were lysed for $45 \mathrm{~min}$ on ice in a buffer containing $10 \mathrm{mM}$ Tris buffer (pH 7.4), $150 \mathrm{mM} \mathrm{NaCl}, 5 \mathrm{mM}$ EDTA, and $0.5 \%$ Triton $\mathrm{X}-100$. We vortexed the lysates before centrifugation at $10,000 \mathrm{~g}$ for $20 \mathrm{~min}$. Supernatants containing DNA were extracted with equal amounts of neutral phenol, chloroform, isoamyl alcohol mixture (25:24:1, respectively) and were examined electrophoretically on $1.5 \%$ agarose gels containing $0.1 \mu \mathrm{g} / \mathrm{ml}$ ethidium bromide [26].

\section{Western blotting}

Azurin (synthesized from P. aeruginosa 2453) treated ZR-75-1 cells at 12,24 , and $48 \mathrm{~h}$ along with control were scrapped after treatment for cell lyses by lysis buffer as described by Mandal et al. [26] .

After lyses cell extracts were loaded and separated on a 10\% SDSPAGE gel and was transferred to a nitrocellulose membrane. 5\% BSA (Bovine serum albumin) was used to block the membrane before adding the primary antibodies (1: 1,000 dilution, precise for proteins like p53, PARP, caspases-3 Bax, Bcl-2, and $\beta$ - actin; Cell Signaling Technology, Inc., Danvers, MA, USA). Membranes were then incubated with antirabbit IgG-HRP (1: 3,000 dilution), and anti-mouse IgG-HRP (1:2,000 dilution) procured from Santa Cruz Biotechnology, Santa Cruz, CA) 30 min. The blots were developed for visualization using an ECL detection kit (Sigma Aldrich Inc., St Louis, MO, USA.

\section{Topological analysis of ZR-75-1}

Morphological variations, cell shrinkage, and DNA fragmentation in ZR-75-1 were observed under scanning electron and light microscopy. ZR-75-1 cells were cultured on sterile glass in RPMI medium supplemented with $5 \% \mathrm{CO}_{2}$ at $37^{\circ} \mathrm{C}$ for $24 \mathrm{~h}$. After $24 \mathrm{~h}$, azurin (synthesized from $P$. aeruginosa 2453) was added with ZR-75-1 for 48 $\mathrm{h}$ incubation. Cells were harvested by trypsin/EDTA and centrifuged for $5 \mathrm{~min}$ at $1,000 \mathrm{rpm}$ at room temperature. The supernatant was then decanted. Dried pellets were treated with $2.5 \%$ glutaraldehyde in distilled water for $45 \mathrm{~min}$ in hybrid oven shaker at $37^{\circ} \mathrm{C}$. Before dehydration with ethyl alcohol at different concentrations (30\%, 50\%, $70 \%, 95 \%$, and $100 \%$ ) for 5-10 min, cells were washed three times with PBS for $5 \mathrm{~min}$. Cells were fixated using hexamethyl disilazane (HMDS) for scanning electron microscopy (SEM) observation. For observation in the light microscope, ZR-75-1cells were seeded in $30 \mathrm{~mm}$ petri dish. We added $\mathrm{IC}_{50}$ of azurin (synthesized from $P$. aeruginosa 2453) and incubated it for $48 \mathrm{~h}$. After incubation, we photographed the cytoplasm of the cancer cell [27].

\section{Results}

\section{Azurin purification on chromatography}

A $250 \mathrm{mg}$ dry cell paste of all strains was centrifuged, ammonium precipitated, and dialyzed. The dialysate was blended with DEAE cellulose beads to remove the flavor proteins and unwanted proteins. Smaller proteins $(3-5 \mathrm{kDa})$ and higher proteins $(5-80 \mathrm{kDa})$ were eluted

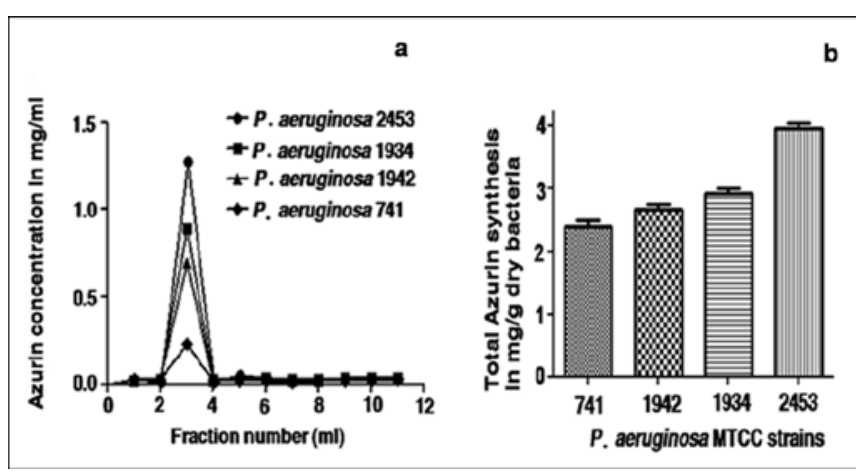

Figure 1: Synthesis of Azurin from $P$. aeruginosa strains. (a) Azurin formed thick bands in CM cellulose column chromatography during their purification process. Later this was eluted by ammonium acetate buffer $(\mathrm{pH} 4.65)$. All $P$. aeruginosa strains, particularly $P$. aeruginosa 2453 strain, showed maximum amount of azurin production. (b) Bar (mean \pm S.E) shows the synthesis of the azurin by various $P$. aeruginosa strains: The production of azurin was enhanced by adding CuSo $4(5 \mu \mathrm{g} / \mathrm{ml})$ and $\mathrm{KNO} 3(0.02 \mu \mathrm{g} / \mathrm{ml})$ in the culture medium under facultative anaerobic condition. 
Citation: Ramachandran S, Sarkar S, Mazumadar A, Mandal M (2011) Azurin Synthesis from Pseudomonas Aeruginosa MTCC 2453, Properties, Induction of Reactive Oxygen Species, and p53 Stimulated Apoptosis in Breast Carcinoma Cells. J Cancer Sci Ther 3: 104-111. doi:10.4172/1948-5956.1000069

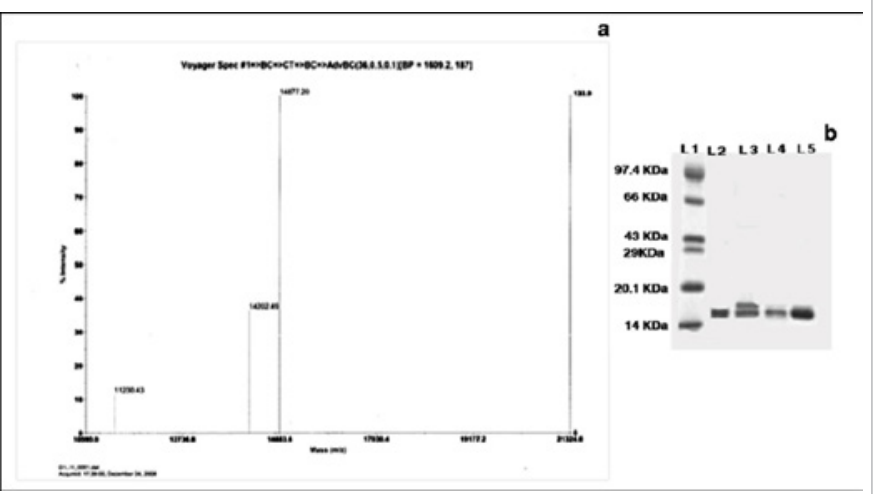

Figure 2: Characterization of azurin. (a) The Fractions collected from CM cellulose were analyzed by MALDI-TOF using Nitrogen laser at $337 \mathrm{~nm}$, confirming the $14 \mathrm{kDa}$ molecular weight of azurin. (b) The molecular weight was further confirmed by running the purified secreted azurin from all strains using $12 \%$ SDS-PAGE. Lane 1: standard molecular weight marker; Lane 2: azurin from $P$. aeruginosa MTCC 1934; Lane 3: azurin from $P$. aeruginosa MTCC 1942; Lane 4: azurin from $P$. aeruginosa MTCC 741; Lane 5: azurin from $P$. aeruginosa MTCC 2453.
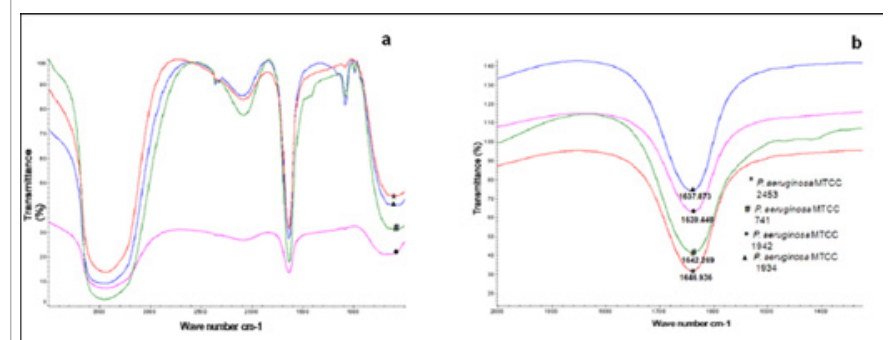

Figure 3: Secondary structure analysis by FTIR. Azurin from all $P$. aeruginosa strains were dissolved in $0.02 \mathrm{M}$ PBS for analysis in Fourier Transform Infra-red (FTIR) spectroscopy. It showed azurin has $\mathrm{C}=\mathrm{O}$ (protein backbone) stretching, a unique nature of the amide I band which is a characteristic feature of $\beta$-structure. FTIR spectrum also revealed there is a shift differences among azurin, synthesized by strains. Our FTIR analysis showed peak around 1646.936 in $P$. aeruginosa 2453 whereas, others showed peak around 1642.269, 1639.446 1637.873 for $P$. aeruginosa $741,1942,1934$ respectively.

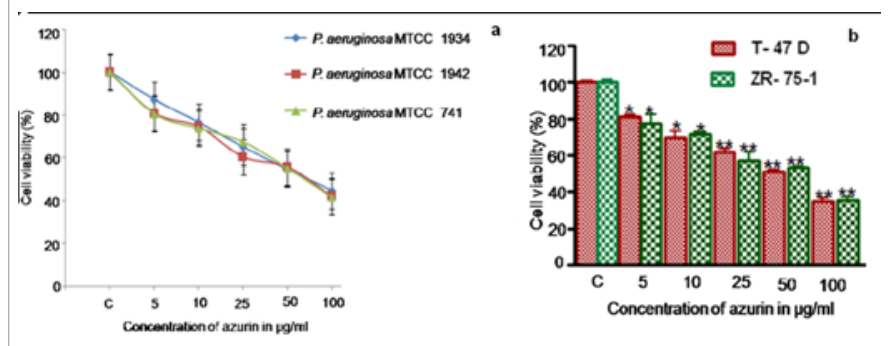

Figure 4: MTT assay for azurin secreted by $P$. aeruginosa strains. (a) Azurin purified from $P$. aeruginosa 1934, 1942, 741strains were treated with ZR-75-1 breast cancer cell distinctly for cell viability and was measured by MTT assay. There was a significant growth inhibition of both ZR-75-1 at $I C_{50} 72 \pm$ $3 \mu \mathrm{g} / \mathrm{ml}$. (b) Both T-47D and ZR-75-1 grown in 96-well plate were treated with various concentration of azurin from $P$. aeruginosa 2453 for $48 \mathrm{~h}$. Bar (mean \pm S.E) shows the cell viability (\%) of ZR-75-1 and T-47D cell lines treated with increasing concentration of azurin from all strains. All results are expressed as percentage of control and are mean \pm S.E and statistically analyzed by using test . $p$ values $\left({ }^{*}-0.05,{ }^{* *}-0.01\right.$ were considered significant against control cells.

through G-25 and G-75, respectively. Particulate fraction from G-75 was eluted through CM cellulose. The purified azurin of all strains by CM cellulose are shown in Figure 1a.

\section{Azurin yield from various strains of $P$. aeruginosa}

Azurin production from different microorganisms and different strains of $P$. aeruginosa are varies with their ability may be due to their physiological or antigenic variations. Our current study revealed this fact by observing the closely related strains of $P$. aeruginosa (1934, 741, 2453, and 1942) by adding $\mathrm{CuSo}_{4}$ and $\mathrm{KNO}_{3}$ under facultative anaerobic conditions.

Among four P. aeruginosa MTCC strains (2453, 741, 1942, and 1934), higher yield of azurin was secreted by $P$. aeruginosa 2453(Figure 1b). A $250 \mathrm{~g}$ of cell paste of P. aeruginosa yielded $3.95 \mathrm{mg} / \mathrm{g}$ of azurin.

\section{Azurin properties}

The fraction which showed peak in CM cellulose was collected and analyzed for molecular weight determination to confirm the presence of azurin in the purified compound. The molecular weight was determined by MALDI spectrometer (Figure 2a). Again it was confirmed SDS-PAGE (Figure 2b) by loading azurin protein at different lanes with standard molecular weight marker. Both analyses showed similar results that azurin is a $14 \mathrm{kDa}$ molecular weight protein. SDSPAGE and MALDI results were shown only for P. aeruginosa 2453.

The functional groups of azurin were studied using FTIR spectrum. The presence of the amide I band was indicated by the peak around $1650 \mathrm{~cm}^{-1}$ region, which arises primarily because of the stretching vibration of the main chain of carbonyl groups in the protein backbone coupled with the in-plane N-H bending and C-N stretching modes. Furthermore, the presence of an amide band around $1650 \mathrm{~cm}^{-1}$ signifies a-helix secondary structure of azurin. Azurin synthesized from all strains showed a significant shift in the amide I band (Figure $3 \mathrm{a} \& 3 \mathrm{~b}$ ) with one another, indicating differences in their $\alpha$-helix secondary structure of azurin. The most prominent among all strains is $P$. aeruginosa 2453 which showed peak around 1646.936 whereas, others showed peak around $1642.269,1639.446,1637.873$ for $P$. aeruginosa $741,1942,1934$ respectively. The peaks at 3695 and $3251 \mathrm{~cm}^{-1}$ are the amide A and B bands, respectively, which arise from a Fermi resonance between the first overtone of amide and the $\mathrm{N}-\mathrm{H}$ stretching vibrations. The $1495 \mathrm{~cm}^{-1}$ peak refers to the amide II band, which arises because of the C-N stretching as well as the C-N-H bending motions. The 1352 peak is the amide III band, which arises predominantly because of the in-phase combination of $\mathrm{N}-\mathrm{H}$ in plane bending and C-N stretching vibrations.

\section{Cytotoxicity effect of azurin}

MTT assay was used to determine the antiproliferative effect of anti cancer drugs. T- 47D and ZR-75-1 are breast cancer cells that we treated with azurin at different concentrations along with untreated control (0.1\% DMSO) for $48 \mathrm{~h}$. There was a significant decline in cell proliferation with an increase in the concentration of azurin as shown in Figure $4 \mathrm{a} \& 4 \mathrm{~b}$. The cell growth of both T- 47D and ZR-75-1 were inhibited extensively with an $\mathrm{IC}_{50}$ of $72 \pm 3 \mu \mathrm{g} / \mathrm{ml}$ in $P$. aeruginosa 2453 as comparable to other strains.

\section{Apoptosis effect of azurin}

Propidium iodide (PI) is the most commonly used dye for analysis of cell cycles or DNA content. Cell distributions were classified among subG $_{1}, \mathrm{G}_{0} / \mathrm{G}_{1}$, s, and $\mathrm{G}_{2} / \mathrm{M}$ phases. Azurin purified from all P. aeruginosa strains $(1934,1942,741$, and 2453) was assayed for apoptosis in T- 47D cells for $48 \mathrm{~h}$. Of note, all $P$. aeruginosa strains that evoke apoptosis are shown in Figure 5a \& 5b. Comparatively, the P. aeruginosa strain 2453 showed (49.97\%) significant apoptosis (Figure 5b). Additionally 
Citation: Ramachandran S, Sarkar S, Mazumadar A, Mandal M (2011) Azurin Synthesis from Pseudomonas Aeruginosa MTCC 2453, Properties, Induction of Reactive Oxygen Species, and p53 Stimulated Apoptosis in Breast Carcinoma Cells. J Cancer Sci Ther 3: 104-111. doi:10.4172/1948-5956.1000069

azurin that was secreted by $P$. aeruginosa strain 2453 was assayed for accumulation of sub- $\mathrm{G}_{1}$ phase with T-47D and ZR-75-1 cells. The percentage increase in the sub- $\mathrm{G}_{\mathrm{o}} / \mathrm{G}_{1}$ phase was from $6.02 \%$ (control) to $49.97 \%$ and $1.99 \%$ (control) to 21.55 in T- $47 \mathrm{D}$ and ZR-75-1 cells (Figure 6a\& 6b).

\section{ROS generation in apoptosis}

We treated breast cancer cell (ZR-75-1) with $72 \pm 3 \mu \mathrm{g} / \mathrm{ml}$ of azurin from $P$. aeruginosa strain 2453 at various intervals to measure the ROS level. Of note, an increase in ROS levels implies significant cell damage and programmed cell death. The mean fluorescent intensity was measured along with the controls. Significant increases in the ROS levels from 5.33 (control) to 42.38 ( $24 \mathrm{~h}$ ) are shown in Figure 7a.

\section{Western blot investigation}

Bax (an anti or proapoptotic regulator involved in activation of caspases) is also upregulated by tumor suppressor protein p53, which also promotes $\mathrm{Bax}$ insertion into the mitochondrial membranes. Activation of caspases cleaves DNA interaction with depleted Poly (ADP-ribose) polymerase (PARP) and can deplete the ATP of a cell. We observed a 4-fold increase in p53 levels after $48 \mathrm{~h}$ incubation of $100 \mu \mathrm{g} / \mathrm{ml}$ azurin (from P. aeruginosa strain 2453) treated with ZR75-1. Depletion of Bcl-2 was nearly 3-fold after $48 \mathrm{~h}$ of azurin (from $P$. aeruginosa strain 2453) treatment compared with the control. The expression level of $\beta$-actin was taken as loading control (Figure $7 \mathrm{~b}$ ).

\section{Induction of apoptosis}

Apoptosis induction by azurin (from P. aeruginosa strain 2453) in breast cancer cells was established using DNA fragmentation assay. After 24 and $48 \mathrm{~h}$, we observed discrete ladder pattern. DNA fragmentation indicates the vital role of ROS in the apoptosis, as shown in Figure 7c.
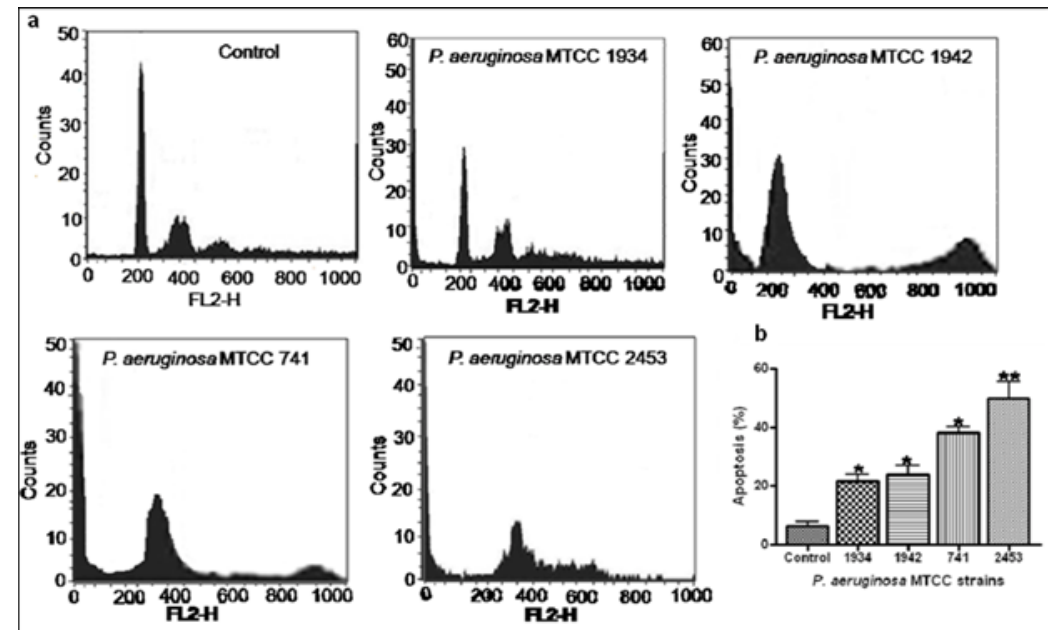

Figure 5: Apoptosis generation by azurin synthesized from $P$. aeruginosa strains. (a)Azurin purified from all four $P$. aeruginosa strains were assayed for apoptosis against ZR-75-1 cancer cells. ZR-75-1 breast cancer cell line was treated with IC 50 value of azurin collected from each $P$. aeruginosa strains for $48 \mathrm{~h}$ and cell cycle analysis was performed. (b) The relative percentage of apoptosis of azurin derived from $P$. aeruginosa strains. Statistical significance was expressed by using student's $t$ test. $P$ values $\left({ }^{*}-0.05\right.$ and ${ }^{* *}$ - 0.01 ) were considered significant compared to control.

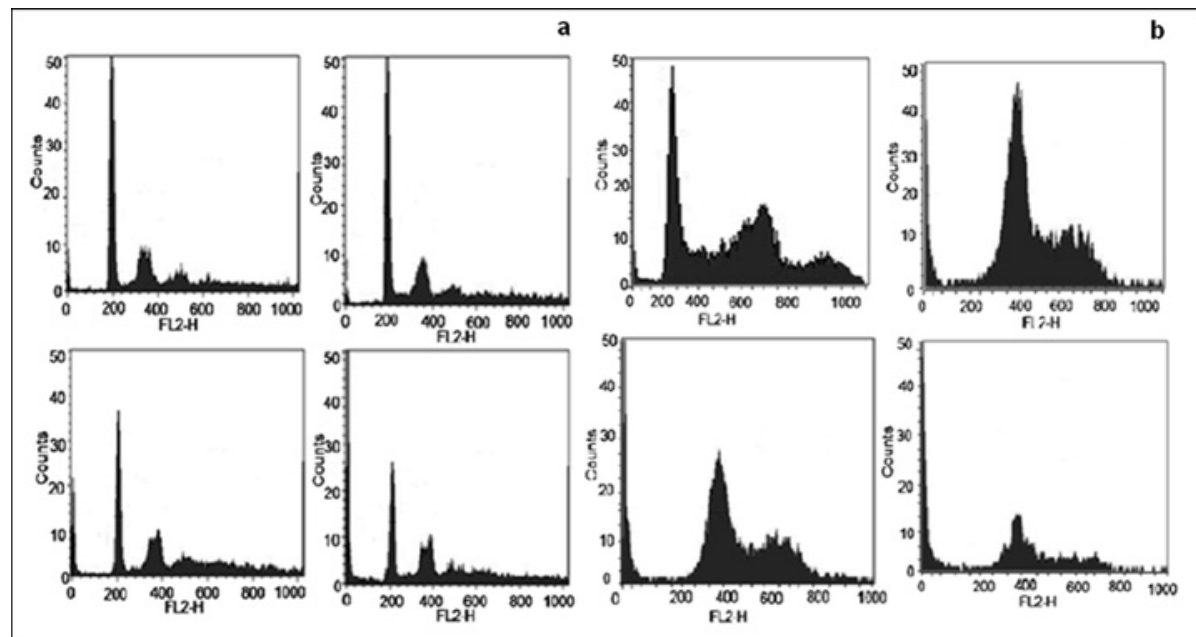

Figure 6: Cell cycle analysis of (a) T-47D and (b) ZR-75-1 breast cancer cells treated with azurin for 12, 24, $48 \mathrm{~h}$ along with control (cells untreated with azurin) secreted from $P$. aeruginosa 2453 strain. 
Citation: Ramachandran S, Sarkar S, Mazumadar A, Mandal M (2011) Azurin Synthesis from Pseudomonas Aeruginosa MTCC 2453, Properties, Induction of Reactive Oxygen Species, and p53 Stimulated Apoptosis in Breast Carcinoma Cells. J Cancer Sci Ther 3: 104-111. doi:10.4172/1948-5956.1000069

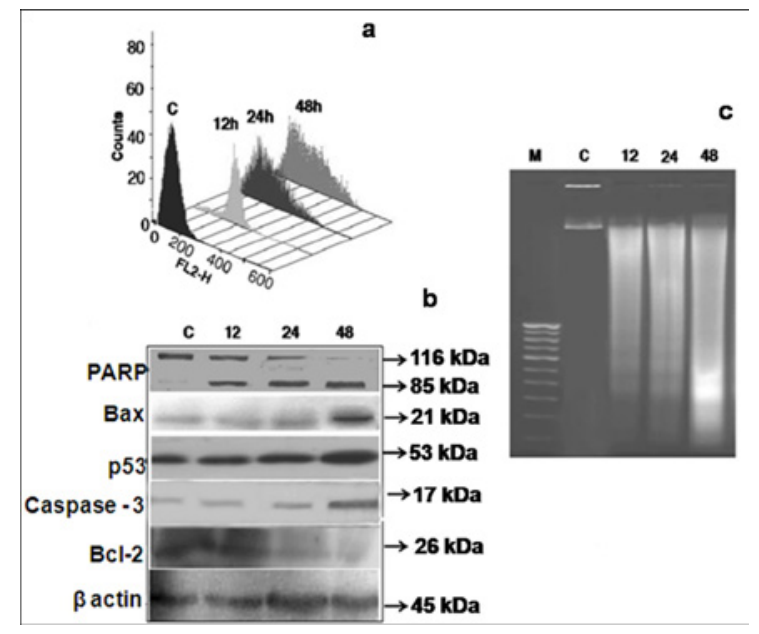

Figure 7: Azurin (secretory product of $P$. aeruginosa MTCC 2453) induced apoptosis in ZR-75-1: (a) ROS levels of ZR-75-1 treated with $72 \pm 3 \mu \mathrm{g} / \mathrm{ml}$ of azurin for $12,24,48 \mathrm{~h}$ along with control were measured after staining with 2', 7' - Dichlorofluorescin diacetate (DCFH-DA) as measured by flow cytometry.. Representative histogram plots of three independent experiments. (a) Western blotting of ZR-75-1 cells treated with $P$. aeruginosa 2453 secreted azurin $72 \pm 3 \mu \mathrm{g} / \mathrm{ml}$ for the indicated time in hours. (c) DNA laddering of ZR-751 cells treated with azurin for the indicated time in hours.

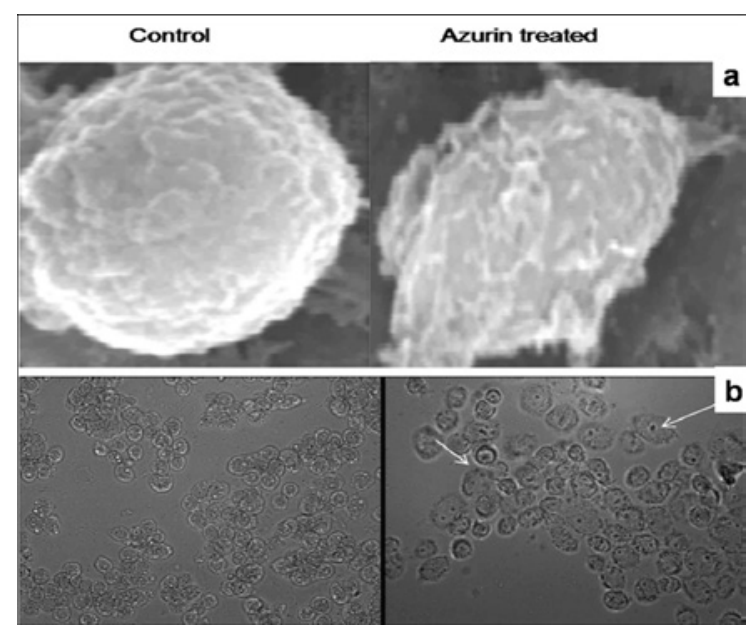

Figure 8: Topological analysis: (a) Scanning electron photomicrograph (SEM) of the surface of breast cancer cell ZR-75-1 treated with azurin (b) Photomicrograph of azurin treated ZR-75-1 cells observed under light microscope at $40 \mathrm{X}$ resolution. Membrane blebbing and granularity distribution of the cancer cells were shown. Arrow indicates apoptotic cells.

\section{Morphological observation of breast cancer cells under SEM and light microscopes}

Azurin-treated and untreated breast cancer cells were photomicrographed under SEM and light microscopes for topological changes of the cell. Cell shrinkage and blebbing, are indicators of typical apoptosis manifestation, were observed in SEM images (Figure 8a).

Cytoplasmic damage and DNA fragmentation after treatment with azurin were observed in light microscopic images. Granular formation, which accumulates in the perinuclear zone, was attributed to induction apoptosis (Figure $8 b$ ).

\section{Discussion}

Even early researchers reported azurin potential against cancer cells $[4,10,13]$ this study revealed which $P$. aeruginosa strain had best enhanced production of azurin than genetically engineered strains and other species. We also reported the strain's synthesized azurin's anticancer effects on breast cancer cells. Our findings clearly showed that the $P$. aeruginosa strain 2453 had a higher production of azurin than that of any other $P$. aeruginosa strains. Moreover, azurin from the $P$. aeruginosa strain 2453 excrete to be potent apoptotic inducer on breast cancer cells than other strains by their ROS generation, and regulating antic cancer proteins. We validated this observation by apoptosisinduction experiments like cell cycle analysis, ROS generation, western blot, DNA fragmentation, and microscopic images.

During the purification process of azurin, we added a protease inhibitor at each step to prevent the degradation of azurin. The presence of the copper ion in the polypeptide chain contributed to azurin's stability, since $5 \mu \mathrm{g} / \mathrm{ml}$ of $\mathrm{CuSo}_{4}$ and the $\mathrm{KNO}_{3}(0.02 \mu \mathrm{g} / \mathrm{ml})$ were the key ingredients as shown by Sutherland [16] in the culture medium that enhanced azurin production.

The lower proteins below $3 \mathrm{kDa}$ in molecular weight were eliminated by dialysis, and the remaining smaller proteins were eluted through DEAE and G-25 chromatography. The higher molecular weight proteins were eliminated in G-75. The CM cellulose purified azurin's presence and was confirmed by SDS-PAGE and MALDI results. Our study confirmed the impact of $\mathrm{CuSO}_{4}$ and $\mathrm{KNO}_{3}$ in the medium that enhances azurin production. Our idea of adding copper in the culture medium was not only for the enhanced azurin synthesis, but to reveal the differences of azurin's stability in the secondary structure for all $P$. aeruginosa strains. The FTIR investigation showed azurin has $\mathrm{C}=\mathrm{O}$ (protein backbone) stretching, which is the unique nature of the amide I band. The presence of the amide band at $1650 \mathrm{~cm}^{-1}$ signifies the $\alpha$-helix secondary structure of azurin. The significant shift among four strains synthesized azurin implies that there was a difference in their secondary structure which may be due to their physiological or genetic variations among strains. The impact of the differences in the secondary structure of azurin synthesized from all four strains tested, were also reflected in the apoptosis generation of all strains.

Even though our MTT results showed very close IC 50 values for all strains, the percentage of apoptosis generation varied among four strains, may be because of secondary structure differences. This confirms our objective that there is a physiological or antigenic variation among all four strains which reflected in structural differences and apoptosis generation.

Even though azurin synthesized from various strains showed significant apoptosis, P. aeruginosa 2453 showed elevated apoptosis than others may be because of their unique secondary structure than others. Therefore, future studies should use azurin synthesized from $P$. aeruginosa 2453 strain.

Azurin-induced apoptosis revealed some important evidence of its potent anticancer effect: (1) azurin inhibits proliferation of breast cancer cells and induces cell cycle arrest at sub- $\mathrm{G}_{1}$ phase, (2) Commotion of mitochondrial cytochrome $\mathrm{c}$ by triggering p53 and Bax as Punj et al. [3] explained. (3) ROS generation indicates activation of p53, (4) p53 induction modulates the level of expression of apoptosis-inducing proteins like Bcl-2 and Bax, and (5) caspase- 3 also induces apoptosis in breast cancer cells treated with azurin.

Our study findings indicate that azurin exerts a significant 
Citation: Ramachandran S, Sarkar S, Mazumadar A, Mandal M (2011) Azurin Synthesis from Pseudomonas Aeruginosa MTCC 2453, Properties, Induction of Reactive Oxygen Species, and p53 Stimulated Apoptosis in Breast Carcinoma Cells. J Cancer Sci Ther 3: 104-111. doi:10.4172/1948-5956.1000069

antiproliferative effect on breast cancer cells. DNA content of azurintreated breast cancer cells was examined using flow-cytometry; the results revealed an elevated cell population accumulating in sub $\mathrm{G}_{0}-\mathrm{G}_{1}$ phase, which denotes induction of apoptosis. ROS generation in cells plays a vital role in both cellular toxicants and signaling molecules [7]. ROS synthesis in azurin-treated breast cancer cells implies p53 induction for programmed cell death. Tumor suppressor protein p53 is a redox vibrant transcription factor, which eventually decides the cellular response to range of stressed that persuades genomic instability in the cancerous cells. Increased ROS and p53 levels leads to apoptosis in the azurin-treated cells were revealed in our study. Previous studies [3] have indicated that p53 may facilitate apoptosis by triggering target genes including $\mathrm{BH} 3$, a proapoptotic protein that regulates $\mathrm{Bcl}-2$ proteins. Our study illustrated that azurin-induced apoptosis of breast cancer cells was accompanied by downregulation of Bcl-2 and upregulation of Bax, which are the downstream objectives of p53 [28]. Azurin-treated cells showed elevated caspases- 3 levels with due time to evoke apoptosis for programmed cancerous cell death [25]. Finally, we confirmed apoptosis using scanning electron and light microscopes of azurin-treated cells. Treated cells displayed characteristic features of apoptosis, like cell blebbing and membrane shrinkage in SEM. Azurin-induced apoptosis cells in a light microscope showed granule formation, which accumulates exclusively in the perinuclear zone. The DNA fragments and granules localized in the cytoplasm showed an increase in apoptotic induction.

Our results showed that among P. aeruginosa strains (741, 1934, 1942, and 2453), the $P$. aeruginosa strain 2453 showed a higher secretion of azurin as equal to previous studies. $[15,16,18]$. Moreover, azurin from strain 2453 excreted higher percentage of apoptosis than did the other strains tested. Our results established that azurin from $P$. aeruginosa strain 2453 may have an extensive antiproliferative effect on breast cancer cells. To our knowledge, this is the first report showing that azurin from $P$. aeruginosa strain 2453 induces apoptosis and is mediated through the cell growth arrest resulting in cell cycle analysis at subG $\mathrm{G}_{1}$ phase, apoptosis induction via ROS generation, $\mathrm{p} 53$ elevation, and up and down regulation of pro and antiapoptotic proteins. The proportion of azurin required for growth inhibition varies according to the cell line and the concentration of azurin used. Future studies should focus on in vivo experiments like intra lesion injection of azurin (from $P$. aeruginosa strain 2453) in animal models of breast cancer; these types of studies will confirm that azurin (from P. aeruginosa strain 2453) can be used as a potential therapeutic agent in patients with breast cancer.

\section{Acknowledgement}

Authors sincere acknowledges to Mr. Shubadheep Banerjee, senior project fellow, SMST, IIT Kharagpur for his generous help in analyzing FTIR data. Sankar Ramachandran acknowledges the NDF fellowship sponsored by AICTE, New Delhi, India. The authors would also like to acknowledge the central research facility of IIT Kharagpur for providing the facility of MALDI, FTIR and FACS.

\section{References}

1. Fleming A (1980) Classics in infectious diseases: on the antibacterial action of cultures of a penicillium, with special reference to their use in the isolation of $B$. influenzae by Alexander Fleming, Reprinted from the British Journal of Experimental Pathology 10:226-236, 1929. Rev Infect Dis 2: 129-139.

2. Samuilov VD (2003) Microbial therapy of cancer: induction of apoptosis recombinant vaccines and inhibition of angiogenesis. Biochemistry (Mosc). 68: 958-962.

3. Punj V, Bhattacharyya S, Saint-Dic D, Vasu C, Cunningham EA, et al. (2004) Bacterial cupredoxin azurin as an inducer of apoptosis and regression in human breast cancer. Oncogene 23: 2367-2378.

4. Dang LH, Bettegowda C, Huso DL, Kinzler KW, Vogelstein B (2001)
Combination bacteriolytic therapy for the treatment of experimental tumors. Proc Natl Acad Sci USA 98: 15155-15160.

5. Alexandroff AB, Jackson AM, O'Donnell MA, James K (1999) BCG immunotherapy of bladder cancer: 20 years on. Lancet. 353: 1689-1694

6. Pawelek JM, Low KB, Bermudes D (1997) Tumor-targeted Salmonella as a novel anticancer vector. Cancer Res 57: 4537-4544.

7. Goto M, Yamada T, Kimara K, Horner J, Newcomb M, et al. (2003) Induction of apoptosis in macrophages by Pseudomonas aeruginosa azurin: tumor suppressor protein p53 and reactive oxygen species, but not redox activity, as critical elements in cytotoxicity. Mol Microbiol 47: 549-559.

8. Apiyo D, Wittung-Stafshede $P$ (2005) Unique complex between bacterial azurin and tumor suppressor protein p53. Biochem Biophys Res Commun 332: 965968.

9. Punj V, Das Gupta TK, Chakrabarty AM (2003) Bacterial cupredoxin Azurin and its interations with the tumor suppressor protein p53. Biochem Biophys Res Commun 312: 109-114

10. Yang DS, Miao XD, Ye ZM, Feng J, Xu RZ, et al. (2005) Bacterial redox proteins azurin induces apoptosis in human ostersarcoma U2OS cells. Pharmacol Res 52: 413-421.

11. Yamada T, Goto M, Punj V, Zaborina O, Chen ML, et al. (2002) Bacterial redox protein azurin tumor suppressor protein p53 and regression of cancer. Proc Natl Acad Sci USA 99: 14098-14103.

12. Yamada T, Goto M, Punj V, Zaborina O, Kimbara K, et al. (2002) The bacteria redox protein azurin induces apoptosis in $\mathrm{J} 774$ macrophages through complex formation and stabilization of the tumor suppressor protein p53. Infect Immun 70: 7054-7062.

13. Yamada T, Mehta R, Majumdar D, Chakrabarty AM, Das Gupta TK (2006) Azurin, highly potent and selective anticancer agent for breast cancer. $\mathrm{J}$ Clin Oncol 24:13106 (ASCO Annual Meeting Proceedings Part I. Vol 24, No. 18S (June 20 Supplement), 13106).

14. Schuler M, Bossy-Wetzel E, Goldstein JC, Fitzgerald P, Green DR (2000) p53 induces apoptosis by caspase activation through mitochondrial cytochrome $c$ release. J Biol Chem 275:7337-7342.

15. Parr SR, Barber D, Greenwood C (1976) Purification procedure for the soluble cytochrome oxidase and some other respiratory proteins from Pseudomonas aeruginosa. Biochem J 157: 423-430.

16. Sutherland IW (1966) The production of azurin and similar proteins. Arch Microbiol 54: 350-357.

17. Pozdnyakova I, Guidry J, Wittung-Stafshede P (2001) Copper stabilizes azurin by decreasing the unfolding rate. Arch Biochem Biophys 390: 146-148.

18. Van de Kamp M, Hali FC, Rosato N, Agro AF, Canters GW (1990) Purification and characterization of a non-reconstitutable azurin obtained by heterologous expression of the Pseudomonas aeruginosa azu gene in Escherichia coli. Biochim Biophys Acta 1019: 283-292.

19. Fukuo T, Kubota N, Kataoka K, Nakai M, Suzuki S, et al. (1998) Matrix-assisted laser desorption/ionization and electro spray ionization mass spectrometry analysis of blue copper proteins azurin and mavicyanin. Rapid Commun Mass Spectrom 12: 1967-1971

20. Weber K, Osborn M (1969) The reliability of molecular weight determinations by dodecyl sulfate-polyacrylamide gel electrophoresis. J Biol Chem 244: 44064412.

21. Surewicz WK, Szabo AG, Mantsch HH (1987) Conformational properties of azurin in solution as determined from resolution-enhanced Fourier-transform infrared spectra. Eur J Biochem 167: 519-523.

22. Shenker BJ, Datar S, Mansfield K, Shapiro IM (1997) Induction of apoptosis in human T-cells by organomercuric compounds: a flow cytometric analysis. Toxicol Appl Pharmacol 143: 397-406

23. Davis PK, Ho A, Dowdy SF (2001) Biological methods for cell-cycle synchronization of mammalian cells. Biotechniques 30: 1322-1326, 1328 , 1330-1331.

24. Simbula G, Columbano A, Ledda-Columbano GM, Sanna L, Deidda M, et al. (2007) Increased ROS generation and p53 activation in alpha-lipoic acidinduced apoptosis of hepatoma cells. Apoptosis 12: 113-123.

25. Macip S, Igarashi M, Berggren P, Yu J, Lee SW, et al. (2003) Influence of 
Citation: Ramachandran S, Sarkar S, Mazumadar A, Mandal M (2011) Azurin Synthesis from Pseudomonas Aeruginosa MTCC 2453, Properties, Induction of Reactive Oxygen Species, and p53 Stimulated Apoptosis in Breast Carcinoma Cells. J Cancer Sci Ther 3: 104-111. doi:10.4172/1948-5956.1000069

induced reactive oxygen species in p53-mediated cell fate decisions. Mol Cell Biol 23: 8576-8585

26. Mandal M, Younes M, Swan EA, Jasser SA, Doan D, et al. (2006) The Akt inhibitor KP372-1 inhibits proliferation and induces apoptosis and anoikis in squamous cell carcinoma of the head and neck. Oral Oncol 42: 430-439.
27. Kaul-Ghanekar R, Singh S, Mamgain H, Jalota-Badhwar A, Paknikar KM, et al. (2009) Tumor suppressor protein SMAR1 modulates the roughness of cell surface: combined AFM and SEM study. BMC Cancer 9: 350

28. Raffo AJ, Kim AL, Fine RL (2000) Formation of nuclear Bax/p53 complexes is associated with chemotherapy induced apoptosis. Oncogene 19: 6216-6228. 